\title{
Extratos de Piper no controle alternativo de fitonematoides do gênero Meloidogyne em Coffea canéfora
}

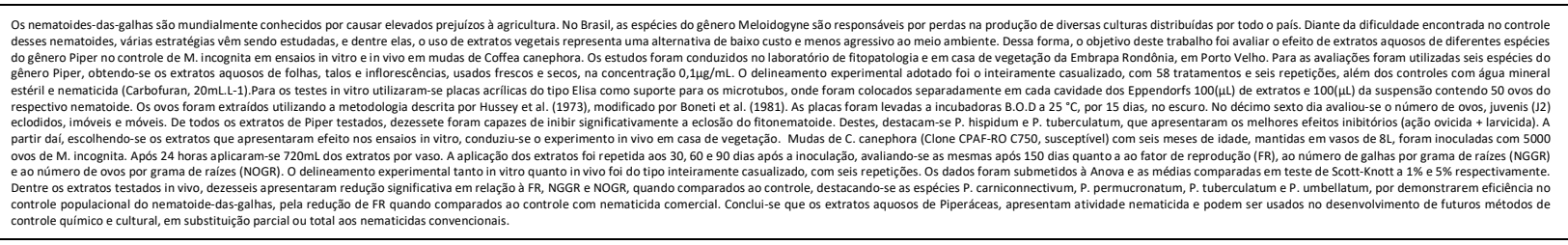

\section{Piper Extracts in Alternative Control of phytonematoids of the genus Meloidogyne in Coffea canephora}

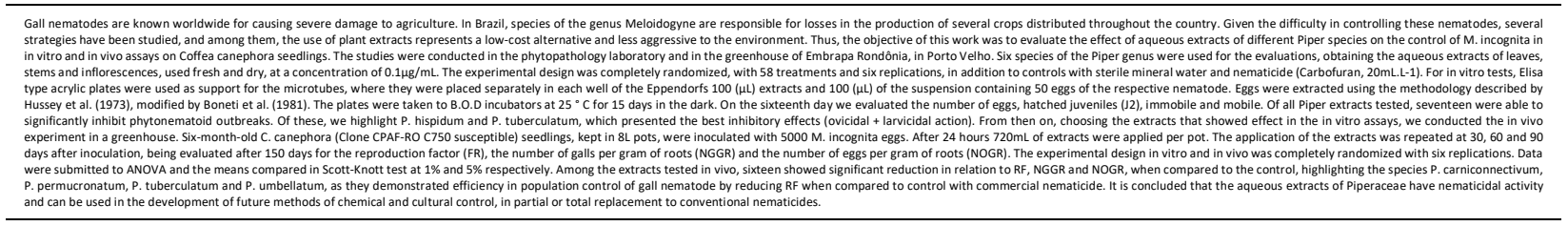

Topic: Desenvolvimento, Sustentabilidade e Meio Ambiente

Simone Carvalho Sangi (i)

Universidade Federal de Rondônia, Brasil http://lattes.cnpq.br/6013814953613677 http://orcid.org/0000-0001-7365-015X

simonecarvalhosangi@gmail.com

\section{José Roberto Vieira Junior (iD)}

Universidade Federal de Rondônia, Brasil http://lattes.cnpq.br/9904275274067824 http://orcid.org/0000-0001-7939-8119 jose-roberto.vieira@embrapa.br

\section{Cléberson de Freitas Fernandes}

Universidade Federal do Ceará, Brasil

http://lattes.cnpq.br/7426209328649448

cleberson.fernandes@embrapa.br

Jessica Silva Felix Bastos

Universidade Federal de Rondônia, Brasil http://lattes.cnpq.br/0634812827491159 jessicafelixbio@gmail.com

\section{Aline Souza da Fonseca (iD) \\ Universidade Federal de Rondônia, Brasil http://lattes.cnpq.br/0456233723446786 http://orcid.org/0000-0002-4019-3412 \\ alinesouzadafonseca@gmail.com \\ Tamiris Chaves Freire (iD) \\ Universidade Federal de Rondônia, Brasil http://lattes.cnpq.br/4372408393666360 http://orcid.org/0000-0002-8938-3751 tamirischavesfreire@gmail.com \\ Liliani Ogrodowczyk (iD) \\ Universidade Federal de Rondônia, Brasil http://lattes.cnpq.br/1320894929836868 http://orcid.org/0000-0001-7497-8114 lili wczyk@hotmail.com}

Jessica Danila Krugel Nunes

Universidade Federal do Rio Grande do Norte, Brasil http://lattes.cnpq.br/6857466494203792 jessica.krugel@ifro.edu.br

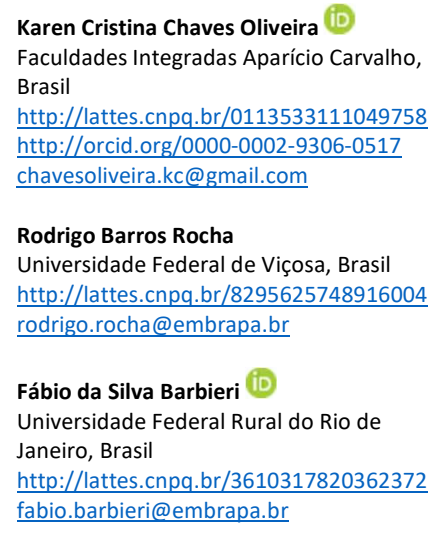

Referencing this:

SANGI, S. C.; VIEIRA JUNIOR, J. R.; FERNANDES, C. F.; BASTOS, J. S. F.; FONSECA, A. S.; FREIRE, T. C.; OGRODOWCZYK, L.; NUNES, J. D. K.; OLIVEIRA, K. C. C.; ROCHA, R. B.; BARBIERI, F. S.. Extratos de Piper no controle alternativo de fitonematoides do gênero Meloidogyne em Coffea canephora. Revista Ibero-Americana de Ciências Ambientais, v.9, n.8, p.212-223, 2018. DOI: http://doi.org/10.6008/CBPC2179$\underline{6858.2018 .008 .0019}$

DOI: 10.6008/CBPC2179-6858.2018.008.0019 


\section{INTRODUÇÃO}

O café é uma importante comoditie, que recebe destaque no mercado mundial, onde é considerado um dos principais produtos agrícolas e agroindustriais de exportação, cultivada em mais de 70 países. Estimase que o agronegócio do café movimente cerca de US\$55bi anuais em todo mundo (DAMATTA, 2007). 0 Brasil é o maior produtor e exportador e segundo maior consumidor de café, (tendo nas espécies Coffea arabica L. e Coffea canephora Pierre ex A. Froehner as principais produtoras), sendo que os maiores Estados produtores são Minas Gerais, São Paulo, Espírito Santo e Paraná.

A despeito dos avanços na cadeia produtiva do café, o setor ainda sofre com os entraves à produção, como as condições edafoclimáticas locais e uma série de problemas fitossanitários que afetam a cultura. Dentre os patógenos que atacam a cultura do cafeeiro, os nematoides das galhas, Meloidogyne spp, podem provocar perdas que variam de 20 a $70 \%$ da produção, dependendo das condições locais e manejo empregado (BARBOSA et al., 2004).

Dentre as espécies que são capazes de parasitar o cafeeiro, o $M$. incognita é apontado como uma das mais importantes e prejudiciais, em função de sua ampla disseminação, elevada capacidade de danificar o sistema radicular, sua plasticidade ambiental, elevada capacidade de sobrevivência no solo e à suscetibilidade da maioria das cultivares ao nematoide, tornando o processo de manejo da doença em áreas infestadas um problema de difícil solução e um sério risco à implantação de novas áreas de café (CASTRO et al., 2008).

Levantamentos realizados por Vieira Junior (2008) e Vieira Junior et al. (2015) sobre a disseminação do nematoide das galhas nos municípios produtores de café no estado de Rondônia, confirmaram a presença predominante de Meloidogyne $M$. incognita e M. exígua como as espécies de maior ocorrência que foi verificada em quase todos os municípios avaliados, sendo a espécie de $M$. incognita a constitui um fator limitante para a obtenção de alta produtividade em cafeeiros.

Dessa forma, o uso de nematicidas comerciais é um dos métodos de controle mais utilizados. 0 emprego desses produtos para o controle desses patógenos em algumas áreas de cultivo não tem sido recomendado, dada aos elevados riscos de contaminação ambiental, dos aplicadores e consumidores, além de aumentar os custos da produção. Diante das necessidades novas alternativas que visam preservar o meio ambiente, além do fato de que a relação custo-benefício e novas alternativas precisam ser desenvolvidas para o controle de patógenos do solo (KIMATI et al., 2005; FERRAZ et al., 2010; CARNEIRO et al., 2012; BATISTA et al., 2013).

Nos últimos anos, produtos naturais vêm sendo utilizados na agricultura como fonte de novas moléculas para o controle de pragas e doenças. Um exemplo disto é a utilização de extratos vegetais e óleos essenciais de plantas com propriedades inseticidas e fungicidas (BASTOS et al., 2009; GONÇALVES et al., 2015). Diversos são os trabalhos que demonstram o potencial de plantas como fontes de substâncias nematicidas, como o cravo de defunto, a mostarda, entre outras. Moreira et al. (2015) avaliou o efeito da incorporação da fitomassa de cravo de defunto ao solo após o transplantio (12, 18, 24 e 30 dias). Os 
resultados de incorporação da fitomassa de cravo de defunto ao solo se apresentaram eficiente na redução da população do nematoide 30 dias após o transplantio.

Moccellin (2011), testando a biofumigação, no controle de Rhizoctonia solani, Pythium aphanidermathum e, Sclerotium rolfsii confirmou a eficácia da mostarda-da-índia (Brassica juncea), repolho (Brassica oleraceae) e canola (Brassica napus), apresentou controle satisfatório da doença. O ambiente amazônico é rico em sua diversidade de plantas, as quais têm sido estudadas para os mais diferentes fins, sendo os usos cosméticos, alimentícios e medicinais os mais importantes. Dentre essas plantas de elevado potencial de uso pode-se citar as Piperáceas, plantas cujo interesse medicinal tem sido demonstrado por alguns autores, que comprovaram o poder tóxico de alguns extratos e óleos de algumas espécies do contra o desenvolvimento de insetos e fitopatógenos (FAZOLIN et al., 2007; SOUSA, 2011).

Nesse sentido, dada a urgência na busca de soluções alternativas ao uso dos nematicidas comerciais, em especial para uso no tratamento de mudas de café, o objetivo deste estudo foi investigar o potencial dos diferentes extratos de Piper; em teste in vitro dos extratos aquosos, sobre a eclosão e mortalidade de juvenis de $M$. incógnita do cafeeiro, bem como seu potencial nematicida quando utilizado em aplicações direcionadas em mudas de Coffea canephora.

\section{MATERIAL E MÉTODOS}

\section{Local do experimento e obtenção do material vegetal}

O trabalho foi conduzido na Empresa Brasileira de Pesquisa Agropecuária, Centro de Pesquisa Agroflorestal de Rondônia - EMBRAPA - CPAFRO. As avaliações foram realizadas no laboratório de fitopatologia e casa de vegetação, em Porto Velho, Rondônia. Para os ensaios foram usadas seis espécies do gênero Piper, sendo elas: P. carniconnectivum, P. hispidum, P. tubercullatum, P. nigrum L., P. umbellatum e P. permucronatum, preparados com materiais secos e frescos, de folhas, talos e inflorescências cultivadas em casa de vegetação e em campo experimental, totalizando cinquenta e oito extratos.

As coletas das plantas foram realizadas após aprovação no SisGen, e registradas sob o código de acesso n. A088959. Estas foram realizadas no período de outubro a dezembro de 2016, dentro do Campo Experimental da Embrapa Rondônia em Porto Velho nas coordenadas geográficas (8 53`20` de latitude Sul e 63 $06^{`} 40^{`}$ de longitude Oeste de Grw). E os ensaios foram realizados dentro das Casas de Vegetação e laboratórios da Embrapa Rondônia, localizada no município de Porto Velho (RO).

A partir das plantas coletadas a campo, foram produzidas mudas das espécies a partir de estaquiamento e plantio das mesmas em substrato produzido na concentração 2:1:1 (solo:areia:esterco) em vasos plásticos de 10L. Foram produzidas 50 mudas de cada espécie e estas foram identificadas e mantidas separadas dentro das casas-de-vegetação até a coleta do material vegetal para os testes. 


\section{Obtenção dos extratos brutos aquosos}

O material vegetal das espécies coletadas foi dividido em duas partes iguais. A primeira foi mantida fresca e a segunda parte foi levada à Estufa de Circulação forçada, com temperatura de $45^{\circ} \mathrm{C}$, por 15 dias, para a secagem completa. O material foi macerado com auxílio de almofariz e pistilo e ao qual foi adicionado nitrogênio líquido $\left(\mathrm{N}_{2}\right)$ e transformado em um pó fino, conforme descrito e adaptado de Ferris et al. (1999).

Posteriormente, pesou-se um grama do pó macerado de cada espécie de planta e estes foram colocados em Erlenmeyer com $10 \mathrm{~mL}$ de água mineral estéril, tampados e mantidos sob agitação em Incubadora Shaker refrigerada a 100 RPM por 24 horas à $25^{\circ} \mathrm{C}$. Todos os extratos obtidos foram filtrados em gaze e pano de nylon, a fim de retirar as partículas sólidas, posteriormente foram mantidos em congelador até serem descongelados para os ensaios.

\section{Multiplicação e preparo do inóculo do nematoide}

Os inóculos dos nematoides $M$. incognita usados no experimento foram obtidos a partir de populações puras mantidas em raízes de raízes de tomateiro 'Santa Cruz Kada'. Estas populações foram identificadas por Santos (2017) utilizando a técnica de eletroforese, adaptada de Carneiro et al. (2001). Para o presente estudo, essas populações foram multiplicadas em plantas de chicória (Cichorium endívia) variedade 'Valença', sendo mantidas em casa-de-vegetação. Raízes foram separadas da parte aérea, fragmentadas em pedaços de três $\mathrm{cm}$, e ovos de $M$. incognita, foram extraídos conforme a metodologia proposta por Hussey e Barker, adaptada por Boneti et al. (1981).

\section{Teste in vitro}

Todos os extratos aquosos produzidos a partir do material vegetal coletado foram testados na proporção 1:10 (p/v, g/mL). O ensaio in vitro foi realizado em Microtubos tipo 'Eppendorf' de 250 microlitros $(\mu \mathrm{L})$ usan do placas acrílicas do tipo Elisa como suporte. Pipetou-se $100 \mu \mathrm{L}$ de extratos $+100 \mu \mathrm{L}$ da suspensão contendo 50 ovos do respectivo nematoide. Como testemunhas foram utilizadas água mineral estéril e nematicida Carbofuran $\left(20 \mathrm{~mL}^{\mathrm{L}-1}\right)$.

O experimento foi conduzido em delineamento experimental inteiramente casualizado, com 58 tratamentos e seis repetições. Em seguida as placas foram embrulhadas em papel alumínio e levadas à incubadas tipo B.O.D a $25^{\circ} \mathrm{C}$ por 15 dias. No 16 ㅇ dia após a incubação, avaliou-se o número de juvenis (J2) eclodidos imóveis e móveis e número de ovos presentes. Foram realizadas três contagens de cada repetição, para o número total de ovos, J2 imóveis e móveis. Para confirmar a mortalidade (J2) foi adicionado em cada lâmina $10 \mu \mathrm{L}$ de Hidróxido de Sódio $(\mathrm{NaOH})$ a $0,1 \mathrm{~N}$ (CHEN et al., 2000). A unidade experimental foi representada por uma cavidade da placa de Elisa. Os dados foram submetidos à Anova e as médias comparadas em teste de Scott-Knott a $1 \%$ de probabilidade. 


\section{Planta hospedeira mudas de cafeeiro}

Para instalação do experimento in vivo, foram utilizados vasos de polipropileno de 8,0L de capacidade, contendo uma mistura de solo e areia na proporção de 2:1 (v/v), previamente autoclavados por uma hora, em autoclave a $121^{\circ} \mathrm{C}$. Mudas de café Coffea canephora, do clone 723 suscetível, foram produzidas em tubetes de $300 \mathrm{~mL}$ contendo substrato comercial estéril no Campo Experimental da Embrapa em Ouro Preto do Oeste.

\section{Teste in vivo}

Trinta dias depois de transplantadas, estas foram inoculadas uma suspensão contendo 5.000 ovos do respectivo nematoide. No decorrer do experimento, efetuaram-se quatro aplicações dos extratos ao solo, sendo a primeira com 24 horas. As outras aplicações dos extratos foram realizadas com intervalo de 30, 60 e 90 dias após a primeira aplicação. Em cada aplicação utilizou-se $720 \mathrm{~mL}$ dos respectivos tratamentos por vaso. Os extratos foram aplicados conforme adaptação da metodologia descrita por Gardiano et al. (2009).

Nos tratamentos testemunhas, utilizou-se água e nematicida Carbofuran $\left(20 \mathrm{~mL}^{\mathrm{L}-1}\right.$. $)$ O nematicida foi aplicado ao solo, somente no tempo de 24 horas após a inoculação da suspensão de ovos. 0 delineamento experimental foi inteiramente casualizado com 19 tratamentos e seis repetições. A unidade experimental foi representada por um vaso contendo uma planta de café. Os dados foram submetidos à Anova e as médias comparadas em teste de Scott-Knott a 5\%.

Aos cento e cinquenta e dois dias após a inoculação das plantas de café, estas foram retiradas dos vasos com solo, separando-se a parte aérea das raízes. Avaliaram-se os seguintes parâmetros: peso da matéria secadas raízes e da parte aérea, o número de galhas e o número de ovos por grama de raízes além do fator de reprodução. Para tanto, após a contagem das galhas do sistema radicular, foram separadas três gramas de raízes, então as mesmas foram cortadas em pedaços de aproximadamente dois $\mathrm{cm}$ para a extração de ovos. Foi utilizada a de Hussey et al. (1973), modificada por Bonetti et al. (1981).

O sistema radicular e folhas remanescentes frescos foram armazenados em saco de papel separadamente elevados à estufa de ventilação forçada a $65^{\circ} \mathrm{C}$, durante 48 horas. Depois de retirados da estufa, foi determinado o peso da matéria seca do sistema radicular e parte aérea. Os dados coletados foram submetidos à análise de variância (ANOVA) na qual, foram consideradas as seguintes variáveis, número de galhas por grama de raízes (NG) número de ovos (NO), fator de reprodução (FR) e peso da matéria seca do sistema radicular (PSSR) plantasse da parte aérea e as médias comparadas em teste de Scott-Knott a 5\% de probabilidade.

\section{RESULTADOS E DISCUSSÃO}

\section{Potencial in vitro de extrato aquosos de espécies de Piper sobre Meloidogyne incognito}

Foram obtidos 58 extratos a partir da solvente água, conforme apresentado no quadro 1. Dos 58 extratos obtidos dezessete demostraram efeito ovicida, quando comparados ao controle água e o 
nematicida. Os resultados foram considerados promissores quando reduziram a eclosão de juvenis de $M$. incognita, conforme indicado na figura 1.

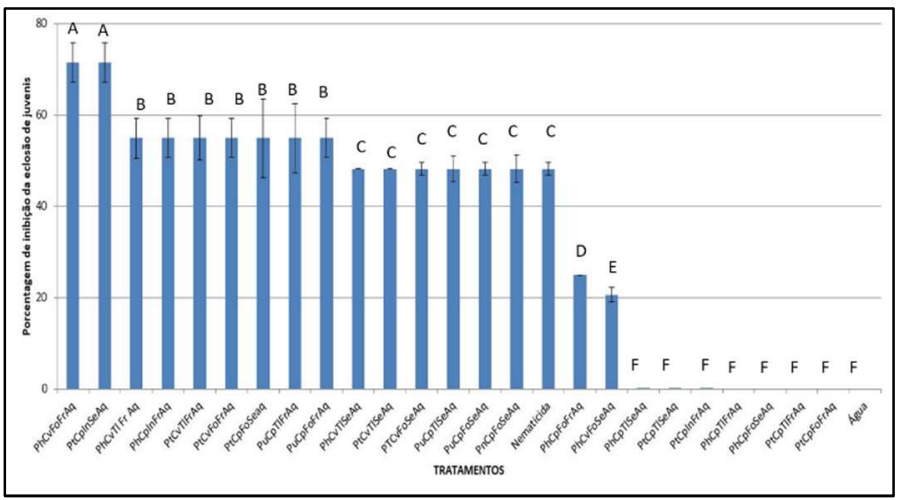

Figura 1: Efeito dos diferentes extratos aquosos de Piper sobre a inibição na eclosão de juvenis de segundo estádio de Meloidogyne. Valores médios seguidos de mesma letra não são diferentes baseados no teste Scott-Knott a $1 \%$ de probabilidade. Legenda: Pt: P. tuberculatum; Pu: P. umbellatum; Pn: P. nigrum; Ph: hispidum; Cv: Casa de vegetação; Cp: Campo; Tl: talo; Fo: folha; In: Inflorescência; Se: secos; Fr: frescos; Aq: Aquoso.

O extrato de Piper hispidum, se mostrou eficiente, reduzindo a eclosão de $J 2$ de $M$. incognita em 75\%, quando comparado com o controle com água. O mesmo foi observado quando analisado o efeito do extrato de Piper tuberculatum, cuja redução foi de $75 \%$ na eclosão de $J 2$ de $M$. incognita em comparação com o tratamento testemunha água (figura 1).

Os extratos de Piper hispidum, $P$. tuberculatum e $P$. umbellatum, em diferentes formas, inibiram em média, 55\%, a taxa de eclosão de $J 2$ em relação às testemunhas nematicida carbofuran e a água (figura 1). Os demais extratos apresentaram algum efeito de inibição, porém igual ao nematicida comercial utilizado. Se, no entanto, forem comparados estes resultados com o controle com água, dezessete extratos apresentaram resultados com ação inibitória.

Os extratos de Piper hispidum advindo de folhas frescas proveniente da casa de vegetação (PhCvFoFrAq) e Piper tuberculatum advindo de inflorescências secas, obtido do campo (PtCplnSeAq), mostraram-se promissores sobre a eclosão de J2 de $M$. Incognita (figura 1). Contudo, estudos relacionando o uso destas plantas no controle de nematoides não foram encontrados na literatura, no entanto, seus constituintes químicos vem demonstrado atividades variadas, entre elas, antioxidante, inseticida, tripanocida e antifúngica (LOPES et al., 2012; VASCONCELOS et al., 2012; BATISTA et al., 2013; SILVA, 2013; MARQUES et al., 2017).

Santos et al. (2010) ao testar extratos das folhas de P. hispidum contra Hypothenemus hampei (Besouros), demostrou ação inseticida. Azevedo et al. (2013), ao testar óleos essenciais de Piper hispidum, Piper tuberculatum Jacq., Piper marginatum Jacq, e Piper sp., mostrou eficiência no controle de fitopatógenos.

Do total de extratos avaliados sobre a inibição total em diferentes formas, destacaram-se quinze extratos que proporcionaram efeito inibitório total significativamente maior ou igual ao nematicida, e quatro extratos que não diferenciaram estatisticamente do controle negativo. $O$ extrato de folha fresca de Piper hispidum, obtido da casa de vegetação, teve ação tanto larvicida quanto ovicida, reduzindo a atividade de 
juvenis a partir das massas de ovos em $70 \%$, sendo significativo quando comparado ao tratamento controle Furadan (figura 2).

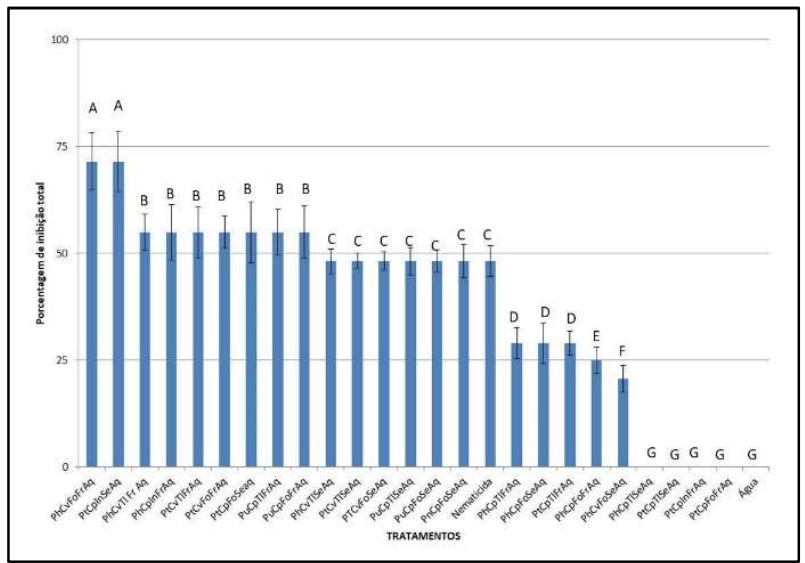

Figura 2: Porcentagem total de inibição no controle $\mathrm{J} 2$ de $M$. incognita in vitro. Valores médios seguidos de mesma letra na são diferentes baseados no teste de Skott-knot a $1 \%$ de probabilidade. Legenda: Pt: $P$. tuberculatum; Pu: $P$. umbellatum; Pn: P. nigrum; Ph: hispidum; Cv: Casa de vegetação; Cp: Campo; TI: talo; Fo: folha; In: Inflorescência; Se: secos; Fr: frescos; Aq: Aquoso.

Para o extrato de inflorescência (seco) de Piper tuberculatum proveniente do campo, além de apresentar ação larvicida, também obteve ação ovicida, demonstrando potencial de controle de $70 \%$, quando comparado ao nematicida Carbofuran e a testemunha (água), a qual reduziu apenas $5 \%$ a eclosão conforme (figura 2). É importante ressaltar que nenhum J2 considerado imóvel conseguiu recuperar a mobilidade quando foi adicionada na câmara de Peters $10 \mu \mathrm{L}$ de hidróxido de sódio $\mathrm{NaOH}$ a $0,1 \%$.

Existem vários estudos com extratos de Piper que tem demostrado pontencial como inseticidas sobre vários insetos (TRINDADE et al., 2012; CASTRO et al., 2008; MIRANDA et al., 2003); no entanto, nenhum estudo foi realizado para avaliar o uso de extratos destas plantas contra Meloidogyne spp.. Mioranza et al. (2016), ao estudar a toxicidade do extrato de Cúrcuma longa na concentração de 10\%, puderam concluir que o mesmo reduziu a eclosão de $M$. incognita em 93,06\% apresentando efeito nematicida, o que também foi observado no presente estudo com os extratos de Piper preparados na mesma concentração (10\%).

Diante desses resultados, é possível concluir que extratos aquosos do gênero Piper podem ser utilizados como forma alternativa de controle de $M$. incognita. Sendo assim, estudos posteriores são essenciais para se conhecer as propriedades ativas dessas plantas responsáveis pela ação nematicida, para verificar se existe especificidade em relação á espécie de nematoide estudada.

\section{Atividade nematicida de extratos de piperáceas no controle dos nematoides-das-galhas do cafeeiro in vivo}

Dos 58 extratos avaliados foram selecionados 19 extratos de diferentes partes das plantas e formas de preparos para realizar os testes in vivo no controle de $M$. incognita. Para os resultados de porcentagem do número de galhas, todos os extratos testados se mostraram eficientes na inibição da reprodução de $M$. incognita, destacando-se os extratos de folhas secas de Piper tuberculatum e talos preparados nas formas fresco e seco de $P$. carniconnectivum que apresentaram redução de $100 \%$ no número de galhas (figura 3 ). 


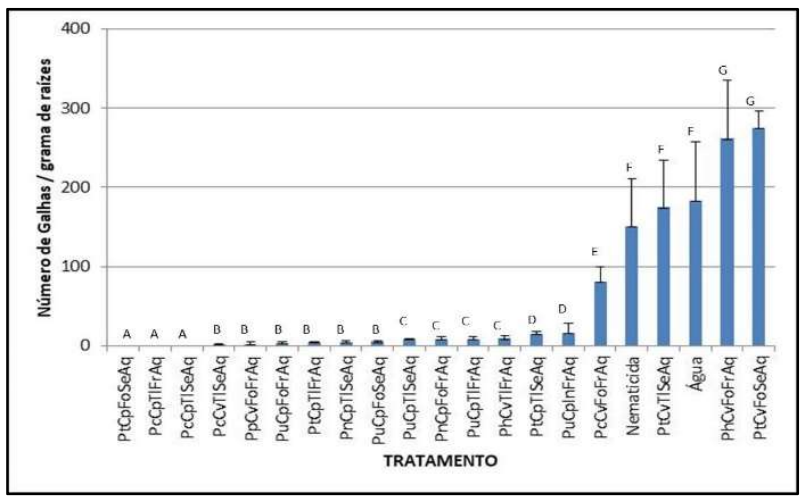

Figura 3: Efeito dos extratos aquosos de Piper sobre o número de galhas (NG) de Meloidogyne incognita em raízes de cafeeiro em condições de casa de vegetação. Médias seguidas de mesma letra não diferem entre si pelo teste de Scott

Knott a 5\% de significância. Legenda: Pt: P. tuberculatum; Pc: P. carniconnectivum; Pp: P. permucronatum; Pu: $P$. umbellatum; Pn: P. nigrum; Ph: hispidum; Cv: Casa de vegetação; Cp: Campo; Tl: talo; Fo: folha; In: Inflorescência; Se: secos; Fr: frescos; Aq: Aquoso.

Borges (2017) trabalhando com extratos de árvore-de-sabão (frutos), pau-de-óleo (folhas), candeia (folhas) e da mistura de extratos de folhas de pau-de-óleo e jatobá-do-cerrado observaram que os extratos causaram maior redução no número de galhas de M. javanica. Costa et al. (2016), ao avaliar o potencial de extratos de folhas de $P$. hispidum no controle do crescimento das bactérias $S$. aureus $e$ B. subtilis, apresentaram resultados bastante satisfatório quanto à inibição bactérias fitopatogênicas, sendo esta uma técnica promissora para o controle de doenças. Destes, somente os extratos de (PhCvFoFrAq e PcCvFoSeAq) não se mostraram eficientes na redução do número de galhas, comparado com o controle negativo e positivo

Foi possível identificar o controle do nematoide $M$. incognita em casa de vegetação, por meio da aplicação dos extratos aquosos ao solo na concentração de $0,1 \mu \mathrm{g} / \mathrm{mL}$. Os extratos mostraram-se eficientes no controle populacional de $M$. incognita. Isto indica que o uso de extratos contribui no manejo e controle de doenças na cultura, podendo ser oferecidos no controle de $M$. incognita na cultura de cafeeiro para os agricultores tendo em vista uma agricultura mais sustentável e ecológica. Os resultados obtidos sobre efeito dos extratos sobre a redução do número de ovos de Meloidogyne incognita por grama de raízes estão apresentados na (figura 4).

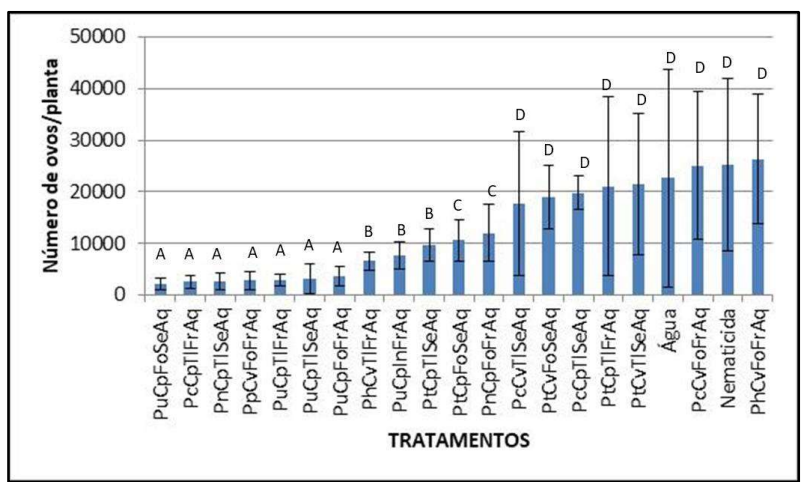

Figura 4: Porcentagem de controle de $M$. incognita, quanto ao número de ovos por planta, em plantas de cafeeiro com 19 tratamentos, aos 150 dias após a inoculação com 5.000 ovos do nematoide. Médias seguidas de mesma letra sobre as colunas não diferem entre si pelo teste de Scott Knott a 5\% de significância. Legenda: Pt: $P$. tuberculatum; Pc: P. carniconnectivum; Pp: P. permucronatum; Pu: P. umbellatum; Pn: P. nigrum; Ph: hispidum; Cv: Casa de vegetação; Cp: Campo; Tl: talo; Fo: folha; In: Inflorescência; Se: secos; Fr: frescos; Aq: Aquoso. 
Os extratos das seis espécies vegetais em diferentes formas de preparos ocasionaram uma redução significativa de acordo com o teste Scott Knott à $5 \%$ de probabilidade, para os extratos de $P$. umbellatum, $P$. carniconnectivum, P. nigrum e $P$. permucronatum, obteve-se inibição na formação de ovos, os quais foram superiores as testemunhas água e o nematicida.

Gardiano et al (2009), testando atividade nematicida de 20 espécies de plantas, pela aplicação ao solo sobre a população de Meloidogyne javanica em plantas de tomateiro em casa de vegetação, observaram que extratos aquosos de folhas de hortelã, bardana e mamona, reduziram o número de ovos por sistema radicular em $81,7 \%, 75,9 \%$ e $56,6 \%$ e o número de galhas em $75,6 \%, 65,7 \%$ e $54,4 \%$. Esses também foram observados por Corboni et al (2013) que, ao testarem extratos aquosos de amora, eucalipto, erva de Santa Maria e capim limão, pela aplicação ao solo, verificaram que houve efeito no controle de Meloidogyne incognita em tomateiro, reduzindo o número de galhas e de ovos formados.

De acordo com os resultados obtidos para o fator de reprodução, todos os tratamentos apresentaram valores menores que um (figura 5), podendo ser observado até mesmo nos controles positivo e negativo. Indicando que apesar das plantas de café Coffea canephora, do clone 723 ser suscetíveis ao ataque do nematoide das galhas, após a aplicação de extratos aplicados ao solo, estes fizeram com que eles se comportassem como resistentes. Segundo Campos et al (2006), a redução da infectividade do J2 em raízes, pode estar associada a ação nematicida dos extratos vegetais. Testes de infectividade devem ser repetidos para confirmar os resultados observados.

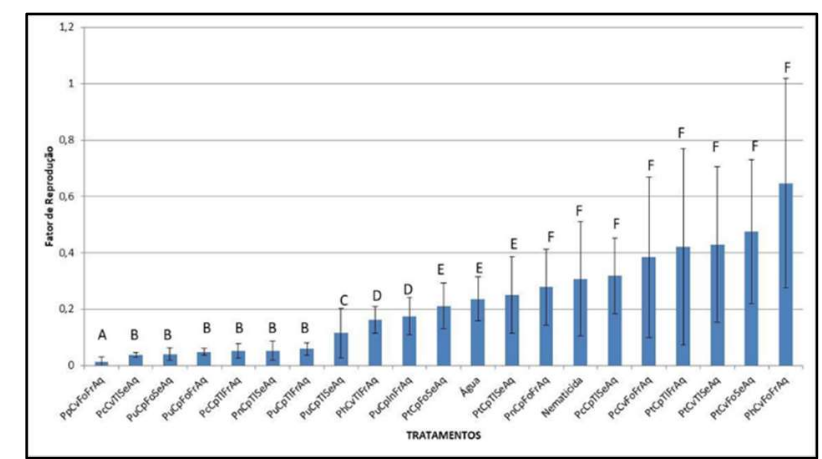

Figura 5: Fator de reprodução (FR) sobre a inibição de Meloidogyne incognita em raízes de cafeeiro, submetidos a tratamentos com extratos aquosos de diferentes espécies do gênero Piper. Médias seguidas de mesma letra sobre as colunas não diferem entre si pelo teste de Scott Knott a 5\% de significância. Legenda: Pt: $P$. tuberculatum; Pc: $P$. carniconnectivum; Pp: P. permucronatum; Pu: P. umbellatum; Pn: P. nigrum; Ph: hispidum; Cv: Casa de vegetação; Cp: Campo; Tl: talo; Fo: folha; In: Inflorescência; Se: secos; Fr: frescos; Aq: Aquoso.

Segundo Santos et al. (2013), é importante identificar os produtos que têm efeito sobre a mortalidade de $M$. incognita, pois podem ocasionar redução no número de nematoides que penetram nas raízes e, deste modo reduzindo ou aumentando em outras variáveis nematológicas, influenciando também fatores de reprodução.

Quanto ao peso da matéria seca do sistema radicular (PSSR) do cafeeiro (figura 6), os resultados confirmam o comportamento evolutivo da variável que, em função dos extratos, de Piper tuberculatum, $P$. 
hispidum, $P$. umbellatum, $P$. carniconnectivum, $P$. nigrum e $P$. permucronatum ao apresentarem um maior desempenho, quando comparados ao controle água.

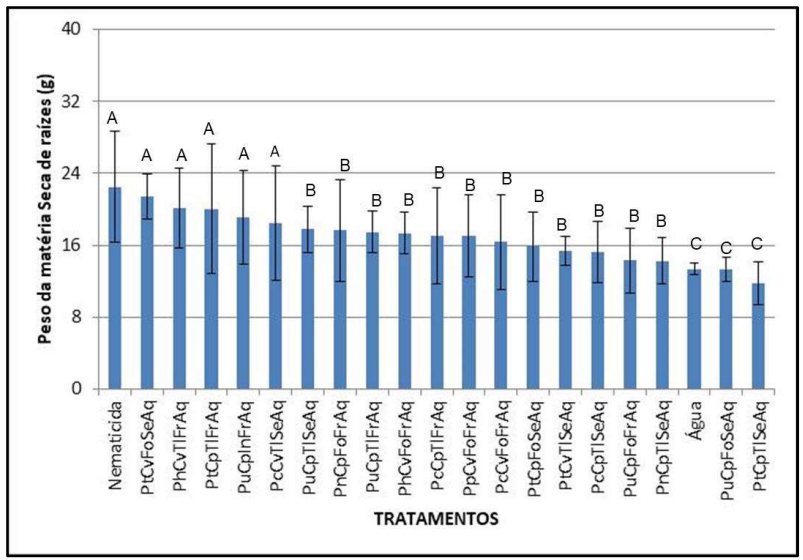

Figura 6: Peso da matéria seca de raizes das plantas de cafeeiros cultivadas sob diferentes tratamentos com extratos inoculadas com nematoide das galhas $M$. incognita. Médias seguidas de mesma letra sobre as colunas não diferem entre si pelo teste de Scott Knott a 5\% de significância. Legenda: Pt: P. tuberculatum, Pc: P. carniconnectivum; Pp: P. permucronatum; Pu: P. umbellatum; Pn: P. nigrum; Ph: hispidum; Cv: Casa de vegetação; Cp: Campo; Tl: talo; Fo: folha; In: Inflorescência; Se: secos; Fr: frescos; Aq: Aquoso.

Observa-se, pois, que os extratos testados, independentemente da espécie, parte da planta, ou tipo de processamento não influenciaram negativamente no desenvolvimento das mudas, mas afetaram a colonização radicular pelo patógeno, reduzindo a população de $M$. incógnita de forma ampla. Para as plantas mantidas como testemunhas negativas, ou seja, aquelas cultivadas em solo infestado e sem tratamento algum observa-se valor médio do peso. Estes dados mostram efeito inibitório sobre infectividade do nematoide das galhas $M$. incognita.

Estes resultados se assemelham ao de Matos (2015) que, testando com extratos aquosos de diferentes espécies vegetais no controle de Meloidogyne em raízes de tomateiro e feijoeiro, observou que as mesmas não afetaram significativamente o peso da matéria seca de raízes, quando comparadas ao controle com água, independentemente da forma de preparo e da parte da planta utilizada nos ensaios.

Ferreira et al. (2013), trabalhando com extratos aquosos de vedélia, erva-de-touro, cravo-dedefunto, girassol mexicano, botão de ouro e zínia sobre Meloidogyne incognita, observaram incremento do peso de parte aérea das plantas avaliadas, em relação à testemunha. Este trabalho se difere dos observados neste experimento, no qual os extratos do gênero Piper não afetaram significativamente o peso da matéria seca do sistema radicular, quando comparadas ao controle com água.

\section{CONCLUSÕES}

De todos os extratos testados in vitro, em condições de laboratório vinte extratos apresentaram efeitos inibitórios do patógeno. O extrato de Piper hispidum obtido a partir de folhas frescas e extrato Piper tuberculatum inflorescência seco, foram capazes de inibir $75 \%$ a mais que o nematicida (ação ovicida +larvicida), sendo sua principal ação, ovicida. 
Nos testes in vivo os extratos Piper permucronatum, $P$. tuberculatum, $P$. carniconnectivum $e$. umbellatum destacaram-se por apresentar maior redução no fator de reprodução, no número de galhas e número de ovos por grama de raiz de $M$. incognita. A utilização de plantas com atividade nematicida se mostrou eficiente sobre o desenvolvimento do patógeno; notadamente sobre a inibição da eclosão de J2 de M. incógnita em cafeeiro. As diferentes partes das plantas promoveram um efeito nematicida sobre $M$. incognita.

\section{REFERÊNCIAS}

BATISTA, L. C. S. O.; FLORENCIO, C. N.; CID, Y. P.; MAGALHÃES, V. S.; CHAVES, D. S. A.; COUMENDOUROS, K.. Bioprospecção de extratos de Jaborandi contra Ctenocephalides felis, Rhipicephalus sanguineus e Rhipicephalus microplus. Revista Brasileira de Medicina Veterinária, v.35, n.2, p.113-118, 2013.

BONETTI, J. I. S.; FERRAZ, S.. Modificação do método de Hussey \& Barker para extração de ovos de Meloidogyne exigua de raízes de cafeeiro. Fitopatologia Brasileira, v.6, n.3, p.553, 1981.

BORGES, D. F.. Efeito nematicida de extratos de plantas do cerrado e óleos essenciais. Dissertação (Mestrado em Produção Vegetal) - Universidade Federal de Viçosa, Rio Paranaíba, 2017.

BARBOSA, D. H. S. G.; VIEIRA, H. D.; SOUZA, R. M.; VIANA, A P.; SILVA, C. P.. Field estimates of coffee yield losses and damage threshold by Meloidogyne exigua. Nematologia Brasileira, v.28, n.1, p.49-54, 2004.

CORBONI, R. Z.; MAZZONETTO, F.. Efeito do extrato aquoso de diferentes espécies vegetais no manejo de Meloidogyne incognita em tomateiro em ambiente protegido. Revista Agrogeoambiental, Pouso Alegre, v.5, n.2, p.61-66, 2013 DOI: http://doi.org/10.18406/2316-1817v5n22013496

CAMPOS, H. D.; CAMPOS, V. P.; POZZA, E. A.. Efeito do tempo e da temperatura de incubação de juvenis de segundo estádio (J2) no teor de lipídio corporal e no parasitismo de Meloidogyne javanica em soja. Fitopatologia Brasileira, v.32, n.4, p.387-393, 2006. DOI: http://doi.org/10.1590/S0100-41582006000400009

CARNEIRO, R. M. D. G.; ALMEIDA, M. R. A.. Técnica de eletroforese usada no estudo de enzimas dos nematóides de galhas para identificação de espécies. Nematologia Brasileira, n.1, v.25, p.35-44, 2001.

CARNEIRO, F. F.; PIGNATI, W.; RIGOTTO, R. M.; FRIEDRICH, K.; FARIA, N. M. X.; BÚRIGO, A. C.; FREITAS, V. M. T.; GUIDUCCI FILHO, E.. Dossiê ABRASCO: Um alerta sobre os impactos dos agrotóxicos na saúde. Rio de Janeiro: ABRASCO, 2012.

COSTA, G. M.; ENDO, E. H.; CORTEZ, D. A. G.; NAKAMURA, T. U.; NAKAMURA, C. V.; DIAS FILHO, B. P.. Antimicrobial effects of Piper hispidum extract, fractions and halcones against Candida albicans and Staphylococcus aureus. Journal de Mycologie Médicale, v.26, p.217-226, 2016. DOI: http://doi.org/10.1016/j.mycmed.2016.03.002
CASTRO, J. M. C.; CAMPOS, V. P.; POZZA, E. A.; NAVES, R. L.; ANDRADE JÚNIOR, W. C.; DUTRA, M.R.; COIMBRA, J. L.; MAXIMINIANO, C.; SILVA, J. R. C.. Levantamento de fitonematóides em cafezais do sul de Minas Gerais. Nematologia Brasileira, Piracicaba, n.1, v.32, p.56-64, 2008.

CASTRO, M. J. P.; SILVA, P. H. S.; PÁDUA, L. E. M.. Potencial de extratos de frutos frescos e desidratados de Piper tuberculatum Jacq. (Piperaceae) no desenvolvimento da lagarta-do-cartucho do milho. Magistra, Cruz das almas, v.22, n.2, 2010

CHEN, S. Y.; DICKSON, D. W.. A technique for determining live second-stage juveniles of Heterodera glycines. Journal of Nematology, v.32, p.117-121.

DAMATTA, F. M.. Ecophysiology of coffee growth and production: review. Brazilian Journal of Plant Physiology, Piracicaba, v.19, n.4, p.485-510, 2007. DOI: http://doi.org/10.1590/S1677-04202007000400014

FERRAZ, S.; FREITAS, L. G.; LOPES, E. A.; DIAS-ARIEIRA, C. R.. Manejo sustentável de fitonematóides. Viçosa: UFV, 2010.

FERREIRA, I. C. M.; SILVA, G. S.; NASCIMENTO, F. S.. Efeito de extratos aquosos de espécies de Asteraceae sobre Meloidogyne incognita. Summa Phytopathologica, v.39, n.1, p.40-44, 2013. DOI: http://doi.org/10.1590/S0100$\underline{54052013000100007}$

FERRIS, H.; ZHENG, L. Plant sources of Chinese herbal remedies: effects on Pratylenchus vulnus and Meloidogyne javanica. Journal of Nematology, v.31, n.3, p.241-263, 1999.

FAZOLIN, M.; ESTRELA, J. L. V.; CATANI, V.; ALÉCIO, M. R.; LIMA, M. S.. Propriedade inseticida dos óleos essenciais de Piper hispidinervium C. DC.; Piper aduncum L.; e Tanaecium nocturnum (Barb. Rodr.) Bur. \& K. Shum sobre Tenebrio molitor L., 1758. Ciências Agrotecnologia, v.31, n.1, 2007. DOI: http://doi.org/10.1590/S1413-70542007000100017

GONÇALVES, A. H.; PEREIRA, A. S.; SANTOS, G.; GUIMARÃES, L. G. L.. Fungitoxicity in vitro of essential oils from Lippia sidoides Cham., Cymbopogon citratus (DC) Stapf. and their major constituents in the control of Rhizoctonia solani and Sclerotium rolfsii. Revista Brasileira de Plantas Medicinais, Botucatu, v.17, n.4, p.1007-1015, 2015.

GARDIANO, C. G.; FERRAZ, S.; LOPES, E. A.; FERREIRA, P. A.; AMORA, D. X.; FREITAS, L. G.. Avaliação de extratos aquosos de várias espécies vegetais, aplicados ao solo, sobre 
Meloidogyne javanica (Treub, 1885) Chitwood, 1949 Evaluation of plant aqueous extracts, added into the soil, on Meloidogyne javanica (Treub, 1885) Chitwood, 1949. Revista Tropical: Ciências Agrárias, Londrina, v.30, n.3, p.551-556. 2009. DOI: http://doi.org/10.5433/1679$\underline{0359.2009 v 30 n 3 p 551}$

ITO, D. S.; SERA, G. H.; SANTIAGO, D. C.; KANAYAMA, F. S.; GROSSI, L. D.. Progenies de café com resistência a nematoides Meloidogyne paranaensis e Raca 2 de Meloidogyne incognita. Coffee Science, v.3, n.2, p.156-163, 2008. DOI: http://doi.org/10.25186/cs.v3i2.87

KIMATI, H.; AMORIM, L.; REZENDE, J. A. M.; BERGAMIN FILHO, A.. Manual de Fitopatologia. Agronômica Ceres, São Paulo, v.1, 2005.

LOPES, J. J.; MARXA, C.; INGRASSIA, R.; PICADA, J. N; PEREIRA, P.; FERRAZ, A. B. F.. Neurobehavioral and toxicological activities of twopotentially CNS-acting medicinal plants of Piper genus. Experimental and Toxicologic Patholocgy, v.64, p.9-14, 2012. DOI: http://doi.org/10.1016/i.etp.2010.05.012

MATOS, S. I.. Estratégias alternativas para o controle de nematoides das galhas. Dissertação (Mestrado em Ciências Ambientais) - Universidade Federal de Rondônia, Porto Velho, 2015.

\section{MOCCELLIN, R.. Espécies de brássicas no controle de} fitopatógenos habitantes do solo. Dissertação (Mestrado) Universidade Tecnológica Federal do Paraná, Pato Branco, 2011.

MARQUES, A. M.; VELOZO, L. S.; CARVALHO, M. A.; HONÓRIO, N. A.; KAPLAN, M. A.; MALECK, M. L.. A potencial natural alternative source for mosquito vector control in Brasil. Journal of Vector Borne Diseases, v.54, n.1, p.61-68, 2017.

MIORANZA, T. M.; MÜLLER, M. A.; INAGAKI, A. M.; FUCHS, F.; RONCATO, S. C.; STANGARLIN, J. R.; KUHN, O. J.. Potencial nematicida e nematostático do extrato de Curcuma longa sobre Meloidogyne incógnita. Revista de Ciências Agroambientais, Alta Floresta, v.14, n.1, p.104-109, 2016.

MIRANDA, J. E.; NAVICKIENE, H. M. D.; COUTO, R. H. N.; BORTOLI, S. A.; KATO, M. J.; BOLZANI, V. S.; FURLAN, M.. Susceptibility of Apis mellifera (Hymenoptera: Apidae) to pellitorine, an amide isolated from Piper

tuberculatum (Piperaceae). Apidologie, v.34, n.4, p.409-415, 2003. DOI: http://doi.org/10.1051/apido:2003036.

MOREIRA, F. J. C.; FERREIRA, A. C. S.. Controle alternativo de nematoide das galhas (meloidogyne enterolobii) com cravo de defunto (tagetes patula I.), incorporado ao solo. HOLOS, v.31, n.1, 2015. DOI:

http://doi.org/10.15628/holos.2015.1600
SANTOS, M. R. A.; SILVA, A. G.; LIMA, R. A.; LIMA, D. K. S.; SALLET, L. A. P.; TEIXEIRA, C. A. D.; POLLI, A. R.; FACUNDO, V. A.. Atividade inseticida do extrato das folhas de Piper hispidum (Piperaceae) sobre a broca-do-café (Hypothenemus hampei). Revista Brasileira de Botânica, v.33, n.2, p.319324, 2010. DOI: http://doi.org/10.1590/S010084042010000200012

SANTOS, M. C. V.; ESTEVES, I.; KERRY, B.; ABRANTES, S.. Biology, growth parameters and enzymatic activity of Pochonia chlamydosporia isolated from potato cyst and root-knot nematodes. Nematology, Leida, v.15, n.4, p.505506, 2013. DOI: http://doi.org/0.1163/15685411-00002695

SILVA, F. R. P.; ALMEIDA S. S. M. S.. Análise fitoquímica e microbiológica da atividade do extrato bruto etanólico da Andiroba, Carapa guianensis Aubl.. Biota Amazônia Macapá, n.4, v.4, p.10-14, 2014. DOI: http://doi.org/10.18561/2179$\underline{5746}$

SILVA, P. H. S.; CARVALHO, D. P.; BARRETO, A. L. H.; CASTRO, M. J. P.. Eficiência de doses do óleo essencial de Piper tuberculatum JACQ sobre adultos do pulgão-preto-do-feijãocaupi Aphis craccivora KOCH. In: CONGRESSO NACIONAL DE FEIJÃO-CAUPI, 3. Anais. Recife: 2013.

SOUSA, E. P. S.. Bioatividade do óleo essencial de piper tuberculatum (jacq.) sobre o percevejo-vermelho-do-caupi crinocerus sanctus (fabr.) (hemiptera: coreidae).

Dissertação (Mestrado em Agronomia) Universidade Federal do Piauí, Teresina, 2011.

TRINDADE, F. T. T.; SILVA, A. A.. Avaliação da atividade larvicida dos extratos de Piper tuberculatum JACQ. e Piper alatabaccum TREL \& YUNCKER sobre as larvas de Anopheles darlingi (Diptera: Culicidae). PROGRAMA INSTITUCIONAL DE BOLSAS DE INICIAÇÃO CIENTÍFICA. Anais. Porto Velho: 2008.

VASCONCELOS, J. N. C.; CARDOSO, N. S. N.; OLIVEIRA, L. M.; SANTANA, J. R. F.; FERNANDEZ, L. G.; OBLITZ, M. G. B.; SILVA, M. L. C.. Indução, caracterização bioquímica e ultraestrutural de calos de aroeira-do-sertão (Myracrodruon urundeuva Fr. All.). Revista Brasileira de Planas Medicinais, v.14, n.4, p.592-597, 2012. DOI:

http://doi.org/10.1590/S1516-05722012000400004

VIEIRA JÚNIOR, J. R.. Levantamento da ocorrência de populações do nematoide-dasgalhas-do-cafeeiro (Meloidogyne sp.) em Rondônia: primeira atualização. Porto Velho: Embrapa, 2015.

VIEIRA JÚNIOR, J. R.; FERNANDES, C. D. F.; RAMALHO, A.; MARCOLAN, A.; FERNANDES, N. A.; DIOCLECIANO, J.; SILVA, D. G.. Levantamento da ocorrência de populações do nematoide das galhas do cafeeiro (Meloidogyne sp.) em Rondônia. Porto Velho: Embrapa, 2008.

A CBPC - Companhia Brasileira de Produção Científica (CNPJ: 11.221.422/0001-03) detém os direitos materiais desta publicação. Os direitos referem-se à publicação do trabalho em qualquer parte do mundo, incluindo os direitos às renovações, expansões e disseminações da contribuição, bem como outros direitos subsidiários. Todos os trabalhos publicados eletronicamente poderão posteriormente ser publicados em coletâneas impressas sob coordenação da Sustenere Publishing, da Companhia Brasileira de Produção Científica e seus parceiros autorizados. Os (as) autores (as) preservam os direitos autorais, mas não têm permissão para a publicação da contribuição em outro meio, impresso ou digital, em português ou em tradução. 